\title{
Occupant comfort in Nearly Zero Energy Buildings (nZEB) by using the building structure for demand side management (DMS)
}

\author{
Ferdinand Sigg $^{1 *}$ and Harald Krause $^{1}$ \\ ${ }^{1}$ Technical University of Applied Sciences Rosenheim
}

\begin{abstract}
This research project aims to increase the application range of Thermally Activated Building Systems (TABS). Usually TABS are used for heating and cooling purpose of buildings. The application range of the usage as energy storage element is limited by the surface temperature of the element to avoid overheating. Via a thermal decoupling of the thermal activated part with insulation from the building structure, it is possible to use TABS as an thermal energy storage. The results show a significant opportunity to timeshift the purchase of energy. The results show that it is possible to use TABS as a thermal energy storage element. It's shown that the purchase of electrician energy for heating purpose can be shifted to economical or ecological optimal time points, for example if renewable energy is abundant in the electrical grid. The heating demand, covered by thermally charged TABS elements can be supplied by a fraction of $95 \%$. Common TABS with a limited surface temperature can reach a coverage rate of $64 \%$. Nevertheless, the mean air temperature increases for this task by $1.1 \mathrm{~K}$ and the heat demand by $15.0 \%$.
\end{abstract}

\section{Introduction}

Through the increasing amount of renewable energy power plants the supply of renewable energy is very fluctuating. Therefore thermal or electrical energy storage systems are needed to decouple the demand of energy use to the supply of cheap and green energy by shifting the operation periods of energy usage.

Various heating systems are available for the heating and cooling of buildings. Mostly fast-reacting systems like air-based solutions, radiators or slower heating systems like underfloor heating systems are used for this purpose. The slowest reacting panel heating system are TABS, also known as Concrete Core Activation.

Generally, Thermally Activated Building Systems (TABS) are used in buildings for heating and cooling. Usually, pipes are cast in the middle layer of a concrete ceiling. A typical structure of a conventional TABS element is shown in Figure 4.

A component, usually concrete, is heated or cooled slightly. The advantage of this temperature conditioning is the use of the enormous storage mass and a large surface, but also resulting in a very an slow component behaviour. When the concrete layer is heated by the pipes, the entire component heats up and releases thermal energy into the room via increased surface temperatures. This heat is usually released via radiation and convection, due to the temperature difference between the room zone and the surface temperature of the building component. Increased heat flow into the room causes the component temperature to decrease and the room temperature to rise.
Thus, the use of building components for the intermediate storage of thermal energy is limited due to surface temperatures.

TABS are usually operated at very low temperatures and still be able to use the building component as a heat emitting surface. When using renewable energies to heat buildings, for example by heat pumps or solar energy, low supply temperatures are highly efficient (low exergy heating systems [1]).

Due to the fluctuating supply of electrical energy from renewable sources, the price of electricity in the power grid also varies very strongly. Figure 6 shows a graph of the exchange electricity spot prices for the German power grid. It is economically and ecologically useful to move the heating time point when electricity is offered cheap, and use the energy for heating purpose consciously and controllably. Efficient ways to use the energy could be via heat pumps. This deliberate time shift on the demand side is called Demand Side Management (DSM). Figure 1 lists various possibilities of DSM.

\footnotetext{
* Corresponding author: ferdinand.sigg $@$ th-rosenheim.de
} 


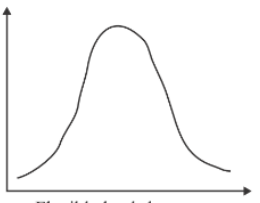
Flexible load shape
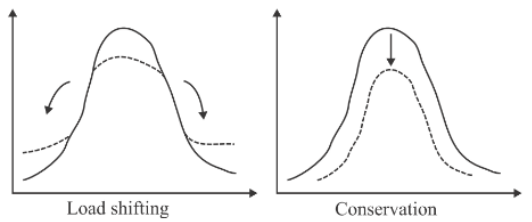

Conservation
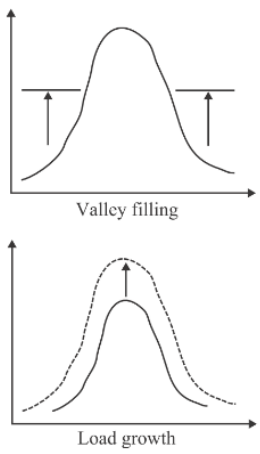

Fig. 1. Opportunities of DSM $[2,3]$

Depending on the time situation, this results in peak shaving, valley filling, load shifting, conservation or a load growth $[2,3]$.

Besides water-based buffer storage, which is usually installed centrally in a building, there is also the possibility to use TABS as energy storage. Due to the limited surface temperatures, the amount of energy that can be stored is limited in order not to fall below comfort criteria, according to EN 15251 [4].

As soon as you want to store energy in a building component without increasing the heat outflow to the room, it is necessary to increase the thermal resistance between the heated concrete and the component surface. In buildings there are often ceiling suspensions due to light installations, ventilation, design or aspects of acoustics. In such cases TABS is usually not recommended due to ceiling suspension, as the heating and cooling capacity is limited.

In those cases it could be reasonable by using the building component not primarily for heating but for storing energy. An exemplary structure can be seen in Figure 5. The attempt is to make a ceiling construction usable as TABS, which before was not suitable for this purpose.

It is investigated how far insulated TABS can be used for buffering energy in the sense of a DSM without causing too much overheating problems for the user.

\section{Method and Model}

This investigation was based on an example room described as a physical model in the simulation environment IDA ICE 4.8. The room cell is described more detailed in [5], but the basic structure is visible in Figure 2. The test room has an available floor area of $12.18 \mathrm{~m}^{2}$. It is a south-facing room with adiabatic interior surfaces. It is therefore assumed that the respective neighboured rooms behave in the same way as the room under investigation. The outer wall facade was defined with a good U-value of $0.16 \mathrm{~W} / \mathrm{m}^{2} \mathrm{~K}$ of a nZEB building, which has a very good outer shell.

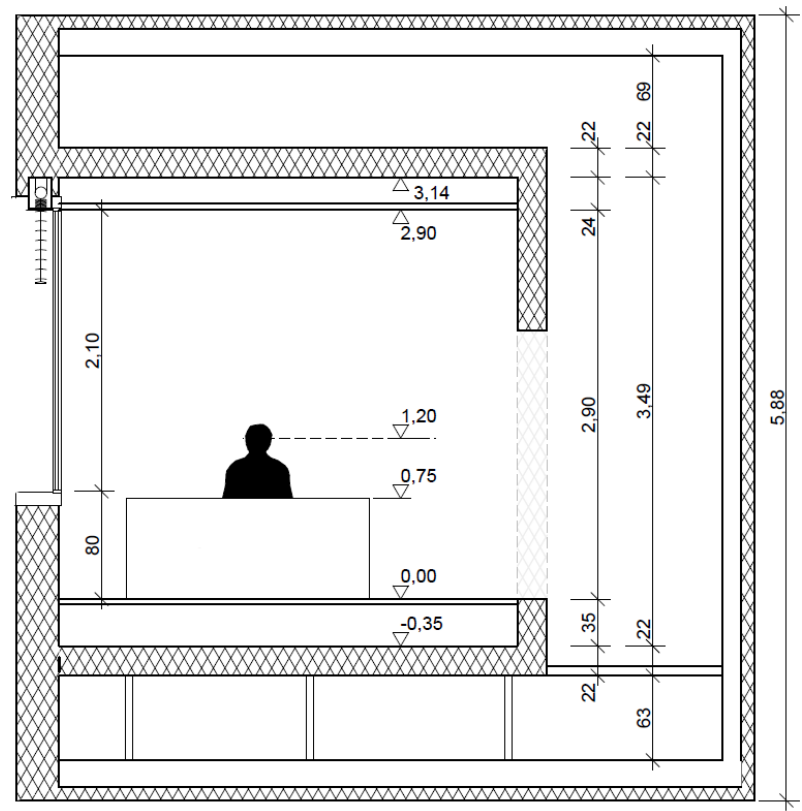

Fig. 2. Geometry of the test room [5]

The building under investigation is located in Munich. The ASHRAE climate data (Munich, 108660) was used. The air exchange rate was defined as $0.3 \mathrm{~h}-1$ with no heat recovery of the ventilation. In the occupied zone of the room, there is a fictitious user who always stays in the room with a metabolic rate of 1 MET. The technical data of the modelled construction of the rest room are shown in Table 1. The window shading is done by a venetian blind, which is drawn an irradiation level of $100 \mathrm{~W} / \mathrm{m}^{2}$ measured outside at the facade.

Table 1. Thermal Envelope of the test room

\begin{tabular}{|c|c|}
\hline $\begin{array}{c}\text { Construction } \\
\text { Element }\end{array}$ & $\begin{array}{c}\text { U-Value } \\
\text { in } \mathrm{W} / \mathrm{m}^{2} \mathrm{~K}\end{array}$ \\
\hline Exterior wall & 0.15 \\
\hline Interior wall & 0.315 \\
\hline Window & $\begin{array}{c}0.6 \\
(\mathrm{~g}=0.54)\end{array}$ \\
\hline
\end{tabular}

The adiabatic interior walls (light-weight made by gypsum panels), the permanently present user, the southfacing façade and the very good building envelope represent a worst-case scenario. Due to the highly insulated building envelope, even small heat gains lead to an increase of room temperature. The examined TABS model (standard IDA-ICE TABS model) is implemented with the resistance model according to [6], but uses a logarithmic temperature difference instead of the thermal resistance along the pipe. The model is shown in Figure 3 , as an excerpt from [7]. 
The heat balance model is described by the following formula:

$$
T_{R t n}=T_{\text {Slab }}+\left(T_{\text {Sup }}+T_{\text {Slab }}\right) * e^{\frac{A}{\left(R_{w}+R_{r}+R_{r x}\right) * c p * m}}
$$

A more detailed description, explanation and validation of the model in a test room can be found in [8].
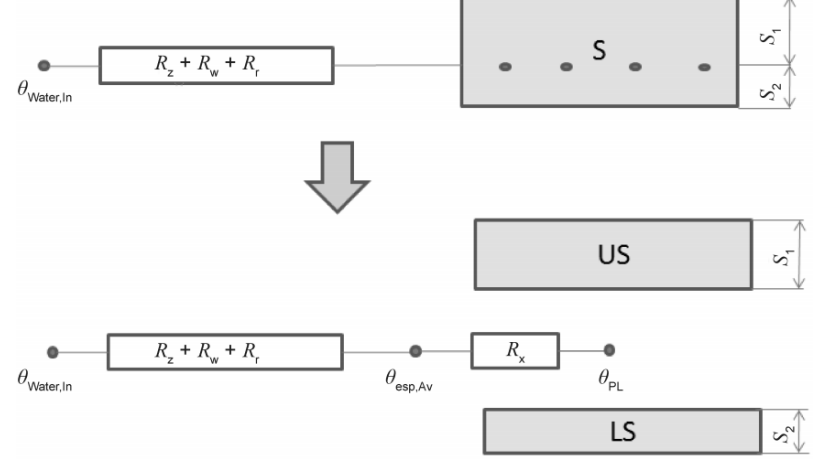

Fig. 3. TABS model, according to DIN EN ISO 11855 4:2016-11

with:

Tsup supply water temperature

Trtn return water temperature

LS lower part of the slab

$R R \quad$ pipe thickness thermal resistance

$R W \quad$ convection thermal resistance at the pipe inner side

$R X \quad$ pipe level thermal resistance

$R Z \quad$ water flow thermal resistance

$S \quad$ slab

S1 thickness of the upper part of the slab

S2 thickness of the lower part of the slab

US upper part of the slab

Oesp,Av: $\quad$ average temperature at the outer side of pipe

$\theta P$ : $\quad$ average temperature at the pipe

levelOwater,I: $\quad$ water inlet temperature

In this study, two very common ceiling constructions are compared with a reference case. The three cases are heated differently. The minimum room temperature is ensured by an ideal heating element, modelled as an ideal perfectly working heating element, in all three cases.

Table 2. Overview of the heating systems

\begin{tabular}{|c|c|c|}
\hline Case & $\begin{array}{c}\text { Main Heating } \\
\text { System } \\
\left.\text { (Setpoint } 21^{\circ} \mathrm{C}\right)\end{array}$ & $\begin{array}{c}\text { Additional heating Element } \\
\text { (non room } \\
\text { temperature control) }\end{array}$ \\
\hline Ref & $\begin{array}{c}\text { Ideal Heating } \\
\text { Element }\end{array}$ & TABS element \\
\hline Case 1 & $\begin{array}{c}\text { Ideal Heating } \\
\text { element }\end{array}$ & TABS element \\
\hline Case 2 & $\begin{array}{c}\text { Ideal Heating } \\
\text { Element }\end{array}$ \\
\hline
\end{tabular}

As a reference case, the room is heated only by an ideal radiator, with a longwave radiation fraction of 40 percent. The ceiling is not equipped with TABS. The reference case serves as an ideal version for a better evaluation of cases 1 and 2. Figure 4 shows the chosen case number 1 . It is the version which is mainly used for efficient heating and cooling of buildings at the lowest possible system temperatures. The TABS is used as a storage element. The required residual energy to avoid temperatures below $21^{\circ} \mathrm{C}$ is provided by the ideal heating element.

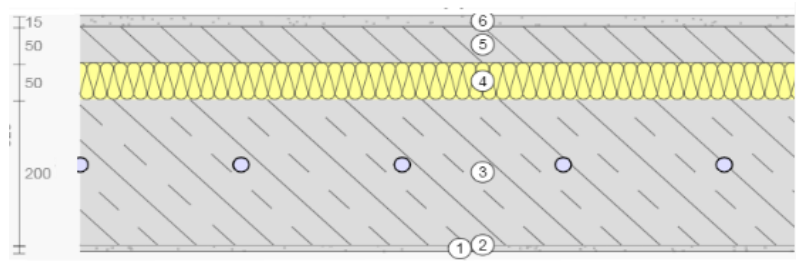

Fig. 4. Conventional construction using a TABS element, used for Case 1

In Case 2, the identical structure is insulated on the lower side with $8 \mathrm{~cm}$. This variant shows a ceiling construction with a suspended ceiling, whereby the space in between is filled with insulating material. The pipe diameter of both is $20 \mathrm{~mm}$ and the center distance is $0.2 \mathrm{~m}$. Case 2 is shown in Figure 5.

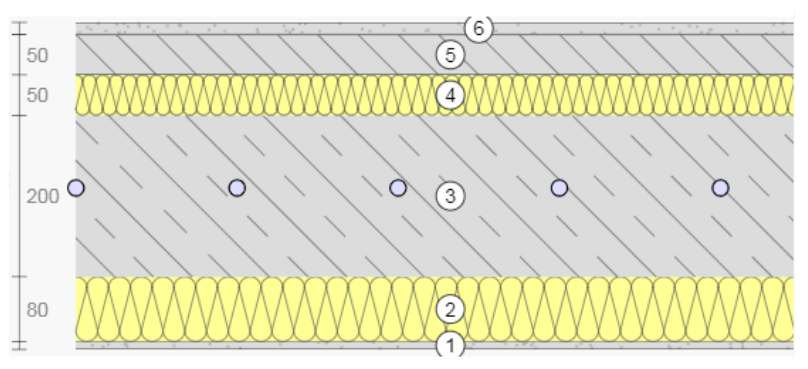

Fig. 5. None conventional TABS element, used in Case 2

Table 3. Various Layers of Fig. 4 and Fig. 5

\begin{tabular}{|c|c|c|c|}
\hline $\begin{array}{c}\text { Material } \\
\text { No }\end{array}$ & $\begin{array}{c}\text { Dim } \\
\text { in } \mathrm{m}\end{array}$ & $\begin{array}{c}\text { Thermal } \\
\text { Conductivity } \\
\lambda \text { in W/mK }\end{array}$ & $\begin{array}{c}\text { Specific heat } \\
\text { capacity } \\
\mathbf{C}_{\mathbf{p} \text { in J/kgK }}\end{array}$ \\
\hline 6 - Gypsum & 0.01 & 0.22 & 1090 \\
\hline 5 - Insulation & $0.08 / 0$ & 0.04 & 750 \\
\hline 4- Concrete & 0.2 & 1.7 & 880 \\
\hline 3- Insulation & 0.05 & 0.04 & 750 \\
\hline 2- Concrete & 0.05 & 1.7 & 880 \\
\hline 1 - Coating & 0.015 & 1 & 920 \\
\hline
\end{tabular}


There is a control strategy for each of the TABS variants. For Case 1, the supply water temperature is controlled by the mean outside air temperature, described [8]. A heating curve calculates the setpoint temperature. It is linear between $26^{\circ} \mathrm{C}$ at an outside air temperature of $-20^{\circ} \mathrm{C}$ and $20^{\circ} \mathrm{C}$ at an outside air temperature of $20^{\circ} \mathrm{C}$. In is shown in Figure 7 (Rule 1).

In Case 2 the heating curve is much steeper. For an outdoor temperature of $-20^{\circ} \mathrm{C}$ the setpoint temperature is $40^{\circ} \mathrm{C}$ and decreases linearly to a setpoint temperature of $30^{\circ} \mathrm{C}$ with an outdoor air temperature of $5^{\circ} \mathrm{C}$. From an outside temperature of $5^{\circ} \mathrm{C}$, the concrete core is no longer heated in both variants to avoid an energy shift in periods when no heating is required. The mass flow is controlled to a spread of $5 \mathrm{~K}$ between supply water temperature and return temperature. As the TABS are primarily operated as storage elements and only the unregulated heat output is used to heat the room, a loading strategy must be defined which is done by a simplified Rule Based Control (RBC). The selected control signal for the DSM for thermal loading in Cases 1 and 2 is the current electricity price on an hourly base. The electricity price (EEX Leipzig) in 2015 , fluctuating between negative values of $-3.1 \mathrm{ct} / \mathrm{kWh}$ and $8.1 \mathrm{ct} / \mathrm{kWh}$, serves as an example. Additional charges for transportation and taxes were not taken into account. The annual trend is shown in Figure 6 and fluctuates strongly on an hourly and seasonal basis.

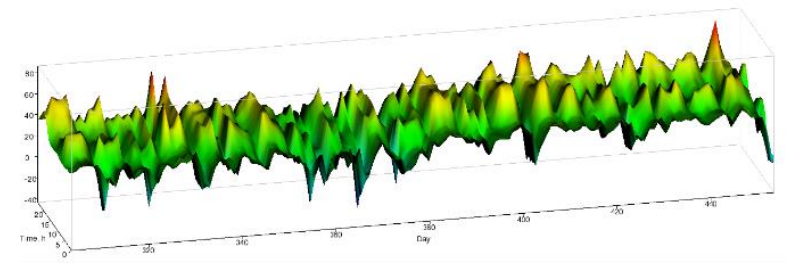

Fig. 6. Strongly fluctuating energy spot-prices in Germany, EEX Leipzig 2015

The current electricity price is compared and evaluated in short-term, mid-term and long-term intervals. The compared time intervals are 1 day $(24 \mathrm{~h}), 1$ week (7 days) and 1 month (30 days). The difference between the current electricity price and the respective electricity price (Rule 1 to 3 ) must be less than $1 \mathrm{ct} / \mathrm{kWh}$ (Rule 1, short-term), 2 $\mathrm{ct} / \mathrm{kWh}$ (Rule 2, mid-term), $5 \mathrm{ct} / \mathrm{kWh}$ (Rule 3, long-therm) to be activated.

Table 4. Overview control settings Rule 1 to 3

\begin{tabular}{|c|c|c|c|}
\hline Rule & $\begin{array}{c}\text { PriceRule,n } \\
\text { (lowest within last) } \\
\text { in ct/kWh }\end{array}$ & $\begin{array}{c}\text { Priceact - } \\
\text { PriceRule,n } \\
\text { in ct }\end{array}$ & $\begin{array}{c}\text { Offset } \\
\text { in K }\end{array}$ \\
\hline 1 & $24 \mathrm{~h}$ & $<1$ & 0 \\
\hline 2 & 7 days & $<2$ & 3 \\
\hline 3 & 30 days & $<5$ & 6 \\
\hline
\end{tabular}

Normally none of the 3 rules are active, because the test room is heated directly by electric heating. If the loading mode is activated (Rule 1 to 3 ), the respective supply water temperatures $\left(T_{\text {sup }}\right)$ depend on the outside air temperature $\left(\mathrm{T}_{\text {ext }}\right)$. The adjusted heating curves with the parallel shift are shown in Fig 7.

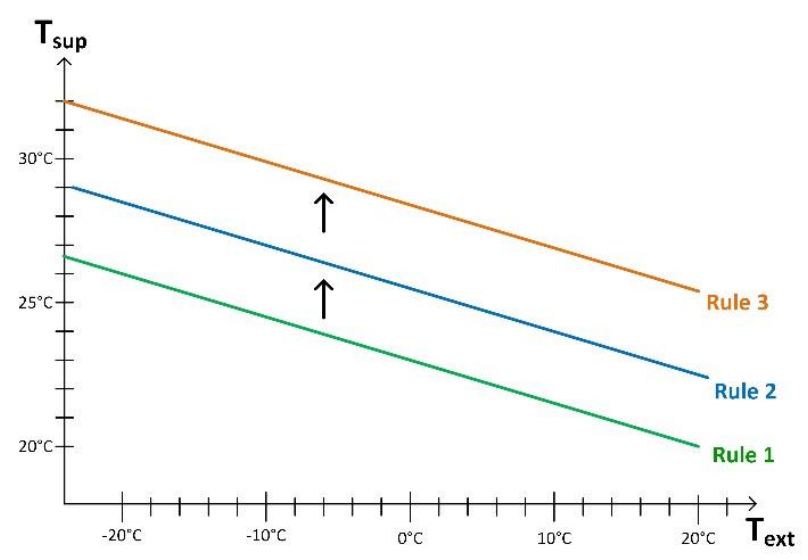

Fig. 7. Adjusted heating curves according to Rule 1 to 3

This means that the less frequently an event occurs, the higher is the loading temperature of the TABS and thus the transferable heat output. If the electricity price approaches a very rare event (rule 3, long-term), the higher raises the flow temperature.

\section{Results}

The results are examined concerning the evaluation of users thermal comfort in the comfort categories of EN 15251 [4] and the thermal behaviour of the test room.

\subsection{Evaluation of thermal comfort}

Figure 8 shows the course of the operative indoor temperature in winter months. It shows the period from November to March, as there was no need for heating before and after caused by the perfect energy standard of the building. Due to the ideal heating element, a minimum temperature of $21^{\circ} \mathrm{C}$ is perfectly maintained. The operative temperature is in the comfort category I of EN 15251 throughout the winter, but there is a comparatively high temperature fluctuation in the warmer months of November and March, when the internal and solar gains increase the temperature inside the building.

The average indoor air temperature is $21.4{ }^{\circ} \mathrm{C}$ during the heating season. The proportion of hours during which the operative temperature is in category IV is extremely low - at $0.1 \%$. 


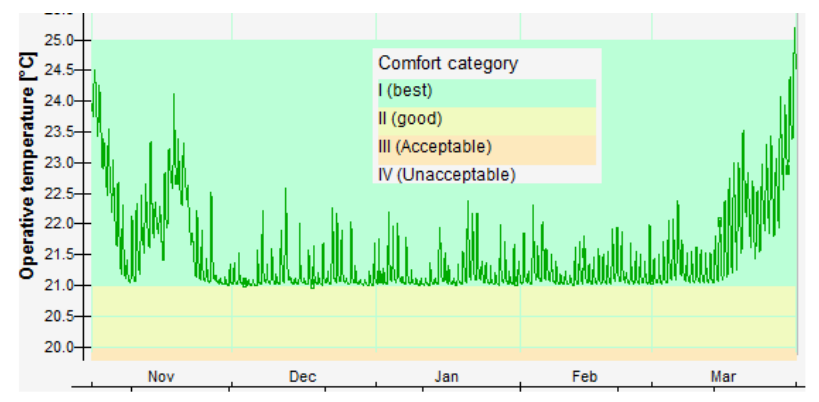

Fig. 8. Operative temperature during winter months in Reference case done by an ideal heating element

In simulation Case 1 it can be seen again that the conventional TABS element leads to minimally increased temperature fluctuations. The minimum temperature is nevertheless guaranteed with the ideal heating element.

Towards the end of the heating season, the very sluggish behaviour of the heated concrete can be noticed. The average room air temperature is $21.7{ }^{\circ} \mathrm{C}$. The use of TABS, therefore, has only a minor influence on the interior comfort of the users and can be rated as very good. The operative temperature outside the category I for only 34 hours, which is $0.9 \%$ of the time.

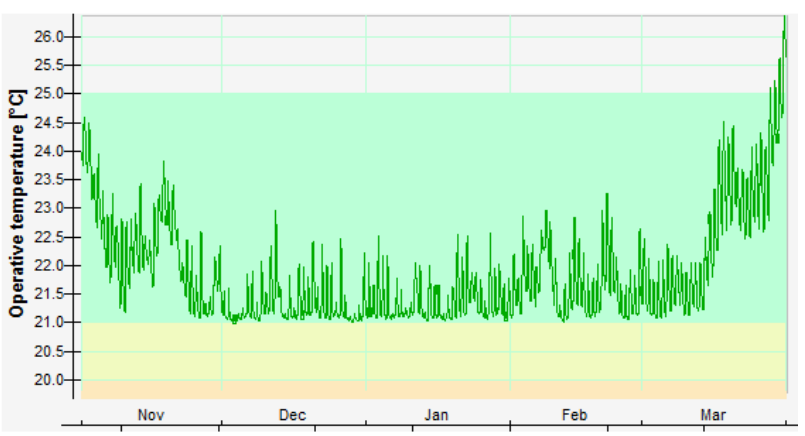

Fig. 9. Operative temperature during winter months in Case 1

Significant higher temperature fluctuations can be seen in Case 2 during the heating season. Due to the much higher heating curve in Case 2, the TABS element is operated at much higher temperatures.

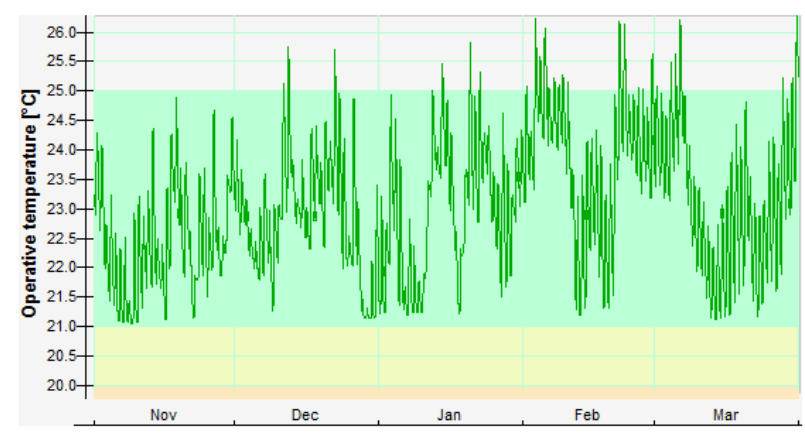

Fig. 10. Operative temperature during winter months in Case 2
During winter, the operative indoor temperature fluctuates very strongly. The average room temperature is slightly higher at $22.8^{\circ} \mathrm{C}$ compared to the reference case and Case 2. Due to the significantly higher temperature fluctuations and the high concrete temperatures, moderate overheating cannot be completely avoided. The operative temperature is $4.6 \%$ of the time in the uncomfortable area of category IV. To sum up, good thermal interior comfort can be achieved in all variants when using a TABS as a passive storage element. For the TABS version with an additional suspended ceiling, the focus should be even more a better temperature control to limit the overtemperature hours. The auxiliary ideal heating element in this example ensures the minimum temperature of $21^{\circ} \mathrm{C}$.

Table 5. Comparison of thermal comfort of all Cases

\begin{tabular}{|c|c|c|}
\hline Case & $\begin{array}{c}\text { Avg. room air } \\
\text { Temperature } \\
\text { in }{ }^{\circ} \mathrm{C}\end{array}$ & $\begin{array}{c}\text { Time in Cat. IV } \\
\text { (not acceptable) } \\
\text { in \% }\end{array}$ \\
\hline Ref & 21.4 & 0.1 \\
\hline Case 1 & 21.7 & 0.9 \\
\hline Case 2 & 22.8 & 4.6 \\
\hline
\end{tabular}

\subsection{Evaluation of thermal and energetic behaviour}

By using an ideal heating element to heat the test room, the specific heating demand of the Reference-Case represents the minimum version and is $11.6 \mathrm{kWh} /\left(\mathrm{m}^{2 *} \mathrm{a}\right)$. In Cases 1 and 2 the heating demand will be higher than the requirement of the Ref.-Case due to the increased interior temperatures (see Tab. 5). The heating demand is covered by the passive, uncontrolled heat emission of the TABS element. The remaining energy requirement to reach the minimum interior temperature of $21^{\circ} \mathrm{C}$ is covered by the ideal heating element.

In the simulation of Case $1,64 \%$ of the heating requirement is covered by the heat emission of the concrete ceiling. The remaining $36 \%$ are covered by the ideal heating element. An increase in the heating curve in Case 1 would lead to an increase of the fraction and higher temperature fluctuations in the interior. 
Table 6. Specific heating hemand of all Cases and Fraction covered by DSM-charged TABS elements

\begin{tabular}{|c|c|c|}
\hline Case & $\begin{array}{c}\text { Spec. space } \\
\text { heat demand } \\
\text { in } \mathrm{kWh} / \mathrm{m}^{2} \mathrm{a}\end{array}$ & $\begin{array}{c}\text { Fraction covered by } \\
\text { TABS element } \\
(0-1)\end{array}$ \\
\hline Ref & 21.4 & 0.0 \\
\hline Case 1 & 21.7 & 0.64 \\
\hline Case 2 & 22.8 & 0.95 \\
\hline
\end{tabular}

The heating requirement in Case 2 is covered to $5 \%$ by the supporting heating element. This means that the TABS element in the ceiling covers $95 \%$ of the heating requirement of the test room. This high percentage is also the reason for the slightly increased average temperature of this variant. To cover $95 \%$ of the heating requirement, the TABS element was only loaded for 497 hours. The element is heated $13.7 \%$ of the time. The passive heat transfer to the room takes place during the whole winter.

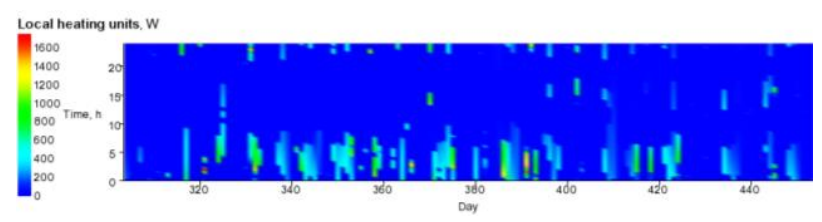

Fig. 10. DSM-controlled charging power of the heated TABS element. Specific maximum at $135 \mathrm{~W} / \mathrm{m}^{2}$ in Case 2

The thermal charging capacity of the element is shown in Figure 10. The maximum specific power is $135 \mathrm{~W} / \mathrm{m}^{2}$. In the reference variant, the maximum specific heat power is $17.5 \mathrm{~W} / \mathrm{m}^{2}$ to cover the interior temperature.

\section{Conclusion}

The results show that very short, highly intensive periods for heating the ceiling are sufficient to cover a high proportion of the required heating demand. Such short periods are necessary for efficient DSM to be able to react flexibly to any situation in the power grid. The presented variants show exemplarily that TABS storage elements are very well suited for DSM. False ceilings with a suspended ceiling, which have not been used for thermal activation up to now, are particularly suitable as energy storages.

Next step will be the examination of optimization the control algorithms.

\section{References}

1. IEA EBC Annex 64, LowEx Communities Optimised Performance of Energy Supply Systems with Exergy Principles, Final Report (2019)

2. P. D. Lund, J. Lindgren, J. Mikkola, J. Salpakari, Renew Sust Energ Rev, Review of energy system flexibility measures to enable high levels of variable renewable electricity, 45, 785-807 (2017)

3. C. Gellings, W. Smith, Integrating demand-side management into utility planning, Proc IEEE 77, 908-18 (1989)

4. European Committee for Standardization, EN-15251: Indoor environmental input parameters for design and assessment of energy performance of buildings addressing indoor air quality, thermal environment, lighting and acoustics (2007)

5. A. Janssens, Reliable building energy performance characterisation based on full scale dynamic measurements, Report of Subtask 1a, 63-72 (2016)

6. M. Koschenz, B. Lehmann, Thermoaktive Bauteilsysteme tabs, EMPA ISBN: 978-3-905594-195 (2000)

7. Deutsches Institut für Normung, Building environment design- Design, dimensioning, installation and control of embedded radiant heating and cooling systems - Part 4: Dimensioning and calculation of the dynamic heating and cooling capacity of Thermo Active Building Systems (TABS), DIN EN ISO 11855-4:2016-11 (2016)

8. P. Nageler, G. Schweiger, M. Pichler, D. Brandl, T. Mach, R. Heimrath, H. Schranzhofer, C. Hochenauer, Validation of dynamic building energy simulation tools based on a real test-box with thermally activated building systems (TABS), ENERG BUILDINGS 168, 42-55 (2018) 